\title{
Infección urinaria en la infancia
}

\author{
FELIPE CAVAGNARO S.M.
}

\section{Urinary tract infection in chilhood}

The urinary tract infection (UTI) is one of the major causes of bacterial infection in children. Therefore an opportune diagnosis, an adequate treatment and a close follow up will prevent chronic renal damage. In this brief article UTI clinical characteristics and recommendations for diagnosis and treatment according to children age are reviewed

Key words: Urinary tract infection; Diagnosis; Treatment; Childhood.

Palabras claves: Infección urinaria; Diagnóstico; Tratamiento; Infancia.

\section{Introducción}

Se define infección del tracto urinario (ITU) como la colonización, invasión y multiplicación, en la vía urinaria, de microorganismos patógenos, especialmente bacterias, que habitualmente provienen de la región perineal (vía ascendente), si bien existe la posibilidad muy infrecuente de infección por vía sistémica (vía hematógena) o directa (cirugías urológicas, traumas abdominales, etc) ${ }^{1}$. Para efectos del presente artículo, nos centraremos en el diagnóstico y manejo de ITU bacteriana adquirida por vía ascendente, situación más frecuente por lejos en relación con las otras alternativas.

Epidemiología. La incidencia exacta de ITU en el niño no se conoce bien, debido especialmente a problemas de definición de infección, diagnóstico clínico y bacteriológico. Se reconoce como la segunda causa más frecuente de infección bacteriana en niños, después de las infecciones respiratorias. Afecta con mayor frecuencia a pacientes de sexo femenino en todas las edades, a excepción de los primeros 3 meses de vida, período en que predomina en los varones. Aproximadamente 3\% de las niñas prepuberales y $1 \%$ de los varones de edad similar han presentado $\mathrm{ITU}^{1-3}$. La recurrencia es de aproximadamente $30 \%$ en mujeres siendo en varones bastante menos frecuente y circunscrita principalmente al primer año de vida ${ }^{3,4}$. Las recaídas ocurren mayoritariamente en los primeros 3 a 6 meses posteriores al episodio de ITU y generalmente son causadas por la misma cepa del episodio original ${ }^{1,3}$.

La certificación del diagnóstico de ITU y su oportunidad son puntos muy importantes en el manejo clínico posterior, para así evitar sobrediagnóstico y daño renal futuro por un diagnóstico tardío, respectivamente. En la actualidad hay consenso de que toda ITU debe ser confirmado por un cultivo de orina que arroje un recuento de colonias igual o superior a 1 colonia/ml de orina si la muestra es tomada por punción vesical, a 10.000 colonias $/ \mathrm{ml}$ si es obtenida por cateterismo vesical o superior a 100.000 colonias $/ \mathrm{ml}$ si la muestra es tomada con bolsa recolectora o de la parte media de la micción (segundo chorro) en un niño sintomático ${ }^{5,6}$. El Comité de Microbiología Clínica de la Sociedad Chilena de Infectología redactó en 2001 sus recomendaciones al respecto, que se adjuntan en Tabla $1^{7}$.

\section{Etiología}

Entre las especies uropatógenas encontramos principalmente bacterias de origen intestinal. El agente etiológico que con más frecuencia se encuentra en la ITU es Escherichia coli (86 a 90\%). El 10 a 14\% restante se distribuye mayoritariamente entre Klebsiella spp, Proteus (vulgaris

Departamento de Pediatría. Escuela de Medicina, Pontificia Universidad Católica de Chile, Santiago, Chile.

Recibido: 29 marzo 2004

Aceptado: 3 enero 2005 
Tabla 1. Interpretación microbiológica del urocultivo y conducta recomendada

\begin{tabular}{|c|c|c|c|c|}
\hline $\begin{array}{l}\text { Recuento de colonias } \\
\text { (UFC/ml) }\end{array}$ & $\begin{array}{l}\text { Condición clínica o } \\
\text { método de recolección }\end{array}$ & Sedimento urinario & $\begin{array}{l}\text { Microorganismo(s) } \\
\text { aislado(s) }\end{array}$ & $\begin{array}{l}\text { Interpretación/ } \\
\text { conducta } \\
\text { recomendable }\end{array}$ \\
\hline 0 & - & $\begin{array}{l}\text { Independiente del } \\
\text { resultado }\end{array}$ & - & Urocultivo negativo \\
\hline Cualquier recuento & Punción suprapúbica & $\begin{array}{l}\text { Independiente del } \\
\text { resultado }\end{array}$ & $\begin{array}{l}\text { Cualquier } \\
\text { microorganismo }\end{array}$ & $\begin{array}{l}\text { Identificación y estu- } \\
\text { dio de susceptibilidad }\end{array}$ \\
\hline 1.000 & $\begin{array}{l}\text { Cateterización } \\
\text { transitoria }\end{array}$ & $\begin{array}{l}\text { Independiente del } \\
\text { resultado }\end{array}$ & $\begin{array}{l}\leq 2 \text { especies } \\
\text { uropatógenas }\end{array}$ & Idem \\
\hline$\geq 10.000$ & $\begin{array}{l}\text { Segunda micción en } \\
\text { paciente especial* }\end{array}$ & $\begin{array}{l}\text { Independiente del } \\
\text { resultado }\end{array}$ & $\begin{array}{l}\leq 2 \text { especies } \\
\text { uropatógenas }\end{array}$ & Idem \\
\hline$\geq 10.000$ & $\begin{array}{l}\text { Orina por catéter } \\
\text { permanente }\end{array}$ & Patológico & $\begin{array}{l}\leq 2 \text { especies } \\
\text { uropatógenas }\end{array}$ & Idem \\
\hline$\geq 10.000$ & Segunda micción & Patológico & $\begin{array}{l}\leq 2 \text { especies } \\
\text { uropatógenas }\end{array}$ & Idem \\
\hline$\geq 100.000$ & Segunda micción & Patológico & $\begin{array}{l}2 \text { uropatógenos }+ \\
\text { otra bacteria con } \\
\text { recuento } 10 \text { veces } \\
\text { menos }\end{array}$ & $\begin{array}{l}\text { Identificación y } \\
\text { susceptibilidad sólo } \\
\text { de los uropatógenos }\end{array}$ \\
\hline$\geq 100.000$ & Segunda micción & $\begin{array}{l}\text { Sin antecedente } \\
\text { del sedimento }\end{array}$ & $\begin{array}{l}\leq 2 \text { especies } \\
\text { uropatógenas }\end{array}$ & $\begin{array}{l}\text { Identificación y estu- } \\
\text { dio de susceptibilidad }\end{array}$ \\
\hline$\geq 100.000$ & - & - & $\begin{array}{l}\geq 3 \text { microorganismos, } \\
\text { sin predominio de } \\
\text { alguno }\end{array}$ & $\begin{array}{l}\text { Polimicrobismo } \\
\text { Solicite nueva muestra }\end{array}$ \\
\hline
\end{tabular}

*Mujer embarazada, paciente diabético o urológico. Ref. 7

y mirabilis), Enterobacter spp, Enterococcus spp y Pseudomonas sp. La proporción de estas últimas bacterias se eleva principalmente en infecciones intrahospitalarias, pacientes inmunocomprometidos, asociadas a malformaciones de la vía urinaria, vejiga neurogénica e instrumentación urológica, condiciones en que también pueden sumarse Citrobacter freundii, Acinetobacter spp y Candida spp. Además, en recién nacidos (RN) es posible encontrar Streptococcus agalactiae (comúnmente llamado $\beta$-hemolítico grupo B), y en adolescentes Staphylococcus saprophyticus ${ }^{1,7}$.

\section{Manifestaciones clínicas}

El espectro clínico de la ITU es muy amplio, pudiendo ir desde una bacteriuria asintomática hasta la urosepsis. El cuadro clínico sugerente de ITU es variable, siendo más específico en la medida en que el niño es mayor y puede verbalizar sus síntomas. Esto debe sensibilizar a los pediatras a sospechar ITU en neonatos y lactantes que se vean enfermos, con o sin fiebre, y que no tengan una causa clara para su compromiso clínico. En todo caso debe siempre considerarse como una causa a descartar en todo niño febril sin foco claro ${ }^{5,6,8}$.

Recién Nacidos: habitualmente parecen gravemente enfermos, con signos sugerentes de sepsis, alternando irritabilidad con letargia, rechazo de alimentación, vómitos, diarrea, ictericia; la fiebre puede estar ausente o presentarse con hipotermia. En aproximadamente un tercio de los RN con ITU coexiste una bacteriemia provocando un cuadro muy severo con síndrome séptico y ocasionalmente meningitis.

Lactantes: destacan signos de enfermedad sistémica, fiebre, vómitos, dolor abdominal, irritabilidad, peso estacionario. Algunos padres logran percibir la orina de mal olor. Evidencias de infección fuera del tracto urinario, como respiratorio o gastrointestinal, no eliminan la posibilidad de existir una ITU en niños pequeños.

Preescolares y niños mayores: habitualmente presentan síntomas referidos a la vía urinaria como disuria, poliaquiuria, urgencia miccional y ocasionalmente enuresis. Estos síntomas tam- 
bién pueden corresponder a otros cuadros tan disímiles y frecuentes a esta edad como vaginitis, vulvitis, oxiuriasis e hipercalciuria. Cuando hay compromiso renal, además del dolor en la(s) fosa(s) lumbar(es), coexisten usualmente síntomas sistémicos como fiebre, compromiso general y vómitos.

En la historia clínica es importante preguntar por episodios febriles previos, especialmente en lactantes (que podrían corresponder a ITU); edad de control del esfínter vesical y de inicio del adiestramiento para su control voluntario; hábito miccional, características del chorro; constipación y antecedentes familiares.

En el examen físico es importante medir la presión arterial, evaluar el crecimiento, buscar la palpación de masas abdominales o de globo vesical; efectuar un meticulosos examen genital buscando malformaciones como epispadia o hipospadias, signos de vulvitis o vaginitis, sinequia de labios menores, fimosis y balanitis; examinar la columna lumbosacra buscando signos de disrafia espinal como nevos, fositas pilonidales, hemangiomas y desviación del pliegue interglúteo ${ }^{6}$.

\section{Diagnóstico y terapéutica}

El manejo está dirigido a prevenir o minimizar el daño renal y a evitar secuelas a largo plazo como la hipertensión arterial y la insuficiencia renal crónica (IRC). Esto es especialmente importante en el lactante y en el preescolar con ITU febril, en quienes es muy elevada la posibilidad de presentar en forma asociada una malformación de vía urinaria con uropatía obstructiva o reflujo vésico-ureteral. De acuerdo a diferentes series, la posibilidad de presentar reflujo vésicoureteral para un lactante bajo un año de edad con una ITU febril oscila entre 30 y $50 \%$, y de portar lesiones obstructivas, en 5 a 10\%. Pueden encontrarse cicatrices renales en aproximadamente $10 \%$ de los niños estudiados por ITU ${ }^{1,4}$.

Los factores que aumentan el riesgo de daño renal se enumeran en la Tabla $2^{6,14}$. En nuestro país, la infección urinaria es causa aproximadamente de $12 \%$ del total de las IRC observadas en niños ${ }^{10}$.

\section{Criterios de diagnóstico}

La confirmación del diagnóstico de ITU debe hacerse a través de cultivo de una muestra de orina tomada en condiciones que sean bacteriológicamente confiables. Junto al cultivo debe tomarse una muestra para examen químico y microscópico de la orina buscando la presencia de bacterias en la tinción de Gram, proteinuria, leucocituria, piuria o cilindros con inclusiones leucocitarias. La presencia de algunos de estos elementos en el examen de orina es sugerente de ITU (Tabla 3), y puede ayudar a seleccionar una población en la que se puede iniciar antibioterapia

Tabla 2. Factores asociados a mayor riesgo de daño renal por ITU

- Edad menor de un año

- Retardo en el inicio del tratamiento antimicrobiano

- Obstrucción de la vía urinaria (anatómica o neurogénica)

- Existencia de reflujo vésico-ureteral severo

- Recurrencia de episodios de pielonefritis aguda

- Existencia de un riñón displásico

Tabla 3. Sensibilidad y especificidad de algunos componentes del análisis de orina

\begin{tabular}{|c|c|c|}
\hline Test & $\begin{array}{c}\text { Sensibilidad } \% \\
\text { (rango) }\end{array}$ & $\begin{array}{c}\text { Especificidad } \% \\
\text { (rango) }\end{array}$ \\
\hline Leucocito esterasa $(+)$ & $(67-94)$ & $78 \quad(64-92)$ \\
\hline Nitritos $(+)$ & $(15-82)$ & $98(90-100)$ \\
\hline Leucocito esterasa o nitritos $(+)$ & $93 \quad(90-100)$ & $72 \quad(58-91)$ \\
\hline Microscopia: leucocitos ${ }^{1}$ & $73 \quad(32-100)$ & $81 \quad(45-98)$ \\
\hline Microscopia: bacteria ${ }^{2}$ & $(16-99)$ & $83(11-100)$ \\
\hline Leucocito esterasa o nitritos o microscopia (+) & $99,8(99-100)$ & $70 \quad(60-92)$ \\
\hline
\end{tabular}

1: > 5 leucocitos/campo 40x.

2: presencia de bacterias en orina sin centrifugar. 
precoz, mientras se espera el resultado del urocultivo ${ }^{1,7,11}$, pero teniendo en mente que pueden haber ITU con análisis citoquímico de orina normal, y al revés, pacientes con examen citoquímico alterado con urocultivo negativo ${ }^{7}$.

Obtención de la muestra de orina. El error diagnóstico más común es la interpretación equivocada de los resultados de los exámenes de orina por una recolección inadecuada de la muestra o por una demora excesiva en el traslado al laboratorio para su procesamiento. La muestra debe ser obtenida por personal entrenado, en el laboratorio o en un sitio cercano a él, con el objeto de disminuir los riesgos de contaminación. Idealmente debe ser obtenida de la primera orina de la mañana, previo aseo genital con agua jabonosa, y sembrada en forma inmediata; si esto último no es posible, debe ser mantenida en refrigeración a $4^{\circ} \mathrm{C}$ hasta el momento de su procesamiento en el laboratorio (por un período máximo de 24 horas $)^{5,7,12}$.

En niños que controlan el esfínter vesical, la muestra de orina debe ser tomada de la parte media de la micción (segundo chorro). En lactantes hospitalizados debe efectuarse cateterismo vesical o punción vesical. En aquellas situaciones en que se utiliza bolsa recolectora, la que debiera reemplazarse cada 30 minutos en caso de no haber emisión de orina, téngase presente que un urocultivo negativo permite descartar el diagnóstico de ITU, pero uno positivo no lo asegura: si se considera que $5 \%$ de los lactantes febriles tienen ITU, y que la especificidad del método es de $\sim 70 \%$, el valor predictor positivo para ITU de un cultivo tomado por bolsa es sólo de $15 \%$. Por esta razón parece necesario insistir en la utilización de técnicas más confiables de obtención de orina (cateterismo vesical, punción vesical) en aquellos niños que aún no con- trolan esfínter, en que el inicio del tratamiento no puede ser retrasado para una posterior confirmación ${ }^{5,13}$.

Infección alta versus baja. Los criterios para definir si el episodio de ITU se acompaña de compromiso renal (ITU alta o pielonefritis aguda) o no (ITU baja), son clínicos, de laboratorio e imagenológicos. Un lactante febril con infección urinaria o un niño mayor con urocultivo positivo, compromiso sistémico, fiebre y dolor en una o ambas fosa(s) renal(es), deben considerarse afectados por una pielonefritis aguda. Apoyan este diagnóstico un hemograma con leucocitosis y desviación a izquierda, VHS $>50 \mathrm{~mm} / \mathrm{h}$, y PCR y procalcitonina altas ${ }^{6,15,16}$. Sin embargo, el método de elección para confirmar la existencia de pielonefritis aguda es la cintigrafía renal estática con Tc99 DMSA ${ }^{14,16,17}$.

\section{Tratamiento}

El tratamiento anti infeccioso de una ITU persigue tres objetivos: erradicar la infección, prevenir el daño renal y resolver los síntomas agu$\operatorname{dos}^{3,5}$.

Frente a la sospecha clínica de un cuadro de ITU, el tratamiento debe ser iniciado precozmente una vez tomadas las muestras para cultivo y examen químico-microscópico. Esto es mandatorio en lactantes febriles, dada la asociación entre retardo en la iniciación de tratamiento y el daño renal secuelar ${ }^{5,14,18}$.

Elección de antimicrobianos según edad y condición clínica del paciente (Tabla 4).

En lactantes bajo 3 meses de edad y en pacientes inmunocomprometidos debe utilizarse la vía parenteral, orientando la elección a cubrir bacilos gramnegativos y asociar una aminopenicilina

Tabla 4. Indicación empírica inicial de antimicrobianos según la edad y la condición basal del paciente

\begin{tabular}{|c|c|c|c|}
\hline Edad/condición clínica & Primera elección & Segunda elección & Observaciones \\
\hline RN-lactante bajo 3 meses & $\begin{array}{l}\text { Cefalosporina } 3^{\mathrm{a}} \text { gen } \\
\text { parenteral + ampicilina }\end{array}$ & $\begin{array}{l}\text { Aminoglucósido + } \\
\text { ampicilina* }\end{array}$ & $\begin{array}{l}\text { Cobertura anti } \\
\text { Enterococcus } \mathrm{sp}\end{array}$ \\
\hline $\begin{array}{l}\text { Lactante } \geq 3 \text { meses y } \\
\text { mayores, mal estado general }\end{array}$ & $\begin{array}{l}\text { Cefalosporina } 3^{\mathrm{a}} \text { gen } \\
\text { parenteral }\end{array}$ & Aminoglucósido* & $\begin{array}{l}\text { Switch a cefalosporina } \\
1^{\mathrm{a}}-2^{\mathrm{a}} \text { gen oral }\end{array}$ \\
\hline $\begin{array}{l}\text { Lactante } \geq 3 \text { meses y } \\
\text { mayores, buen estado general }\end{array}$ & Cefalospina oral $1^{\mathrm{a}}$ gen & Cefalospina oral $2^{\mathrm{a}}$ gen & $\begin{array}{l}\text { Ajustar según cultivo } \\
\text { en } 72 \text { horas }\end{array}$ \\
\hline $\begin{array}{l}\text { Pacientes inmunocomprome- } \\
\text { tidos }\end{array}$ & $\begin{array}{l}\text { Cefalosporina } 3^{\mathrm{a}} \text { gen } \\
\text { parenteral + ampicilina }\end{array}$ & $\begin{array}{l}\text { Aminoglucósido + } \\
\text { ampicilina* }\end{array}$ & $\begin{array}{l}\text { Cobertura anti } \\
\text { Enterococcus sp }\end{array}$ \\
\hline
\end{tabular}

*Ajustar según cultivo en 72 horas para aminorar riesgos de toxicidad renal y ótica. 
Tabla 5. Antimicrobianos más frecuentemente usados en el tratamiento de la ITU y su dosificación en niños

\begin{tabular}{lcc}
\hline Fármaco & Dosis $(\mathbf{m g} / \mathbf{k g} / \mathbf{d i ́ a})$ & Fraccionamiento \\
\hline Nitrofurantoína & $5 \mathrm{a} 7$ & $\mathrm{c} / 8-12 \mathrm{hs}$ \\
Cotrimoxazol (sulfametoxazol/trimetoprim) & $40 / 8$ & $\mathrm{c} / 12 \mathrm{hs}$ \\
Cefadroxilo & 50 & $\mathrm{c} / 12 \mathrm{hs}$ \\
Cefalexina & 50 & $\mathrm{c} / 8 \mathrm{hs}$ \\
Ceftazidima & 100 & $\mathrm{c} / 8 \mathrm{hs}$ \\
Ceftriaxona & $50-75$ & $\mathrm{c} / 24 \mathrm{hs}$ \\
Cefotaxima & 100 & $\mathrm{c} / 6-8 \mathrm{hs}$ \\
Cefixima & 8 & $\mathrm{c} / 24 \mathrm{hs}$ \\
Cefuroxima axetil (oral) & $20-30$ & $\mathrm{c} / 12 \mathrm{hs}$ \\
Amikacina & 15 & $\mathrm{c} / 24 \mathrm{hs}$ \\
Gentamicina & $5-7$ & $\mathrm{c} / 24 \mathrm{hs}$ \\
\hline
\end{tabular}

(ampicilina) activa sobre Enterocococcus sp, tratamiento que se deberá adecuar una vez recibido el resultado del urocultivo y estudio de susceptibilidad in vitro. Pueden utilizarse aminoglucósidos, durante un período no mayor a 72 horas por su potencial toxicidad renal y otológica, a la espera de la información bacteriológica del caso y completar 10 a 14 días de plazo total con otro antimicrobiano de acuerdo a la susceptibilidad in vitro $^{6,19,20 .}$.

En niños sobre tres meses de edad, con pielonefritis aguda y mala tolerancia oral, se recomienda utilizar la vía parenteral, cefalosporinas de $3^{\text {a }}$ generación o aminoglucósidos hasta controlar la fiebre y los síntomas sistémicos, para luego continuar con una cefalosporina oral de $1^{\text {a }}$ (o $\left.2^{\mathrm{a}}\right)$ generación de acuerdo a la susceptibilidad in vitro de la bacteria.

En caso de bacterias resistentes a los antimicrobianos de primera línea y según el estudio in vitro, se puede usar cefalosporinas de $3^{\text {a genera- }}$ ción por vía oral, en terapia ambulatoria.

En casos menos severos puede utilizarse desde el comienzo una cefalosporina oral de $1^{\mathrm{a}} \mathrm{y} / \mathrm{o}$ de $2^{\text {a }}$ generación ${ }^{5,6,19}$.

La duración mínima recomendada para el tratamiento de una pielonefritis aguda es de diez días y para una ITU baja de siete días. Tratamientos más abreviados han tenido menores tasas de erradicación de bacterias en niños. Las bacteriurias asintomáticas (urocultivo positivo en paciente sin síntomas ni alteraciones en el sedimento urinario) no debieran tratarse, con excepción de las adolescentes embarazadas ${ }^{6,19,20}$.

La nitrofurantoína es un excelente medicamento para ser utilizado en ITU bajas y como profilaxis de mantención, pero no debe ser utili- zada en pielonefritis aguda por su baja concentración en el plasma y en el tejido renal ${ }^{3,6}$.

Los medicamentos más recomendados para el tratamiento de la ITU en niños y sus dosis están enumerados en la Tabla 5. El uso de quinolonas (p. ej: ciprofloxacina) ofrece en general, una buena cobertura contra Pseudomonas sp y Proteus sp, y su indicación en niños -restringida por temor a una toxicidad articular, lo que no ha sido corroborado por evidencias clínicas- pudiera ser considerada en situaciones que lo ameriten ${ }^{19}$.

En la Tabla 6 se enumeran aquellas indicaciones para hospitalizar un paciente con ITU: condiciones de riesgo para su diseminación hematógena, que dificultan cumplir adecuadamente el tratamiento o anticipan un fracaso del mismo.

\section{Tabla 6. Indicaciones de hospitalización}

- Recién nacidos y lactante bajo 2 meses de edad

- ITU febril con importante compromiso del estado general, a cualquier edad

- Sospecha de urosepsis

- Hiperemesis que impida la administración de tratamiento oral

- Fracaso de tratamiento ambulatorio (fiebre persistente)

- Antecedentes de malformaciones urinarias (especialmente obstructivas) o fuerte sospecha de ella

- Deshidratación aguda

- Riesgo social

- ITU que afecta a adolescente embarazada 
El tratamiento en el recién nacido debe ser controlado siempre por especialista.

El enfoque diagnóstico y el manejo inicial de la ITU se encuentran resumidos en la Figura 1.

\section{Prevención}

Como medidas generales, en todo paciente con antecedentes de ITU, además de la correc- ción de eventuales alteraciones anatómicas y/o funcionales, debe ponerse especial énfasis en: su adecuada hidratación, que asegure un buen flujo urinario; educación de hábitos miccionales, especialmente un completo y frecuente vaciamiento vesical; corregir la técnica de higiene perineal; combatir la constipación cuando exista ${ }^{6}$.

La lactancia materna parece ofrecer significativa protección contra la ITU en lactantes, por lo

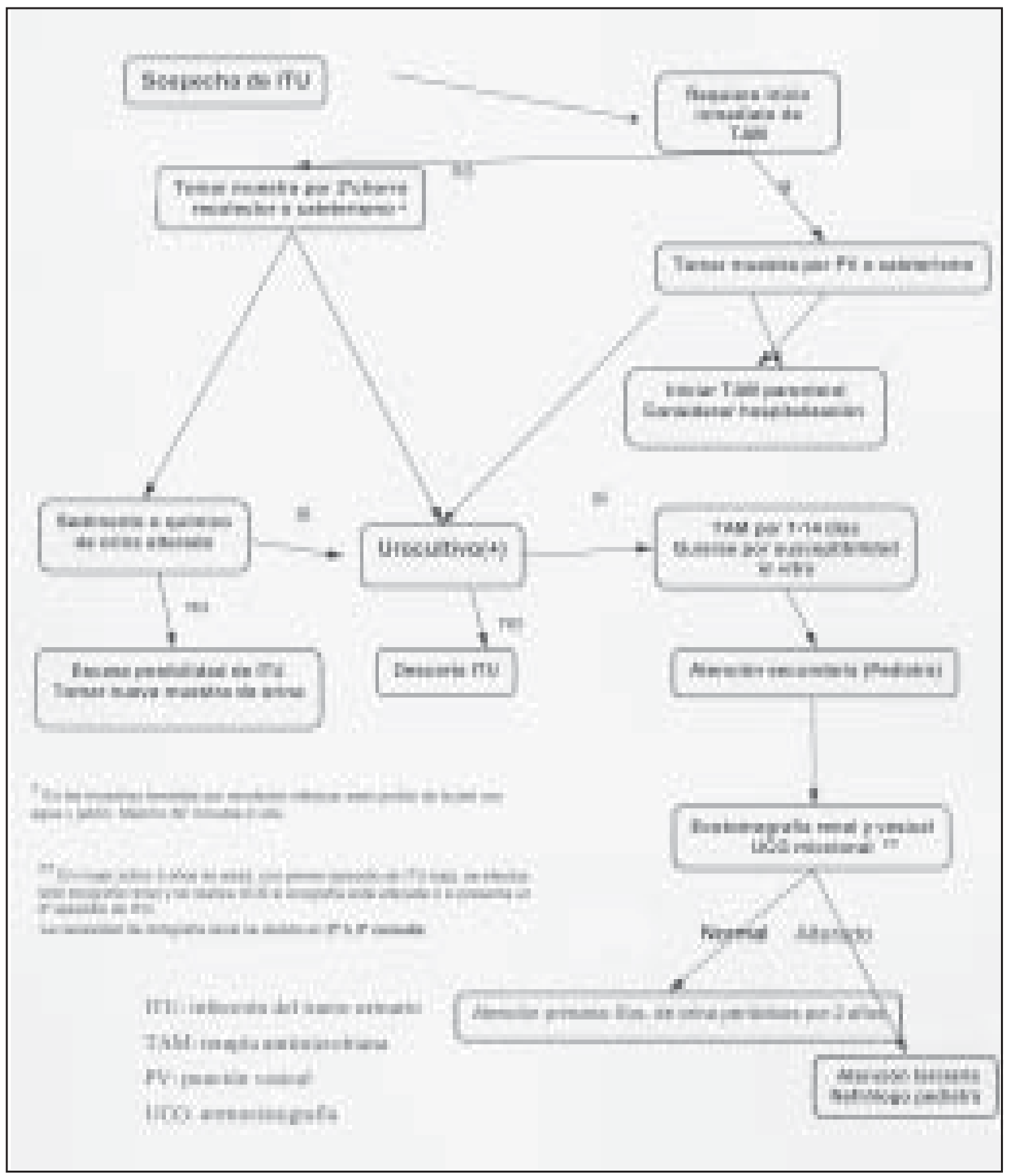

Figura 1. Algoritmo para el estudio de la infección del tracto urinario. 
Tabla 7. Condiciones en que se recomienda quimioprofilaxis de ITU

- ITU recurrente (más de tres episodios en un año), especialmente si son febriles

- Presencia de reflujo vésico-ureteral de tratamiento médico o en espera de resolución quirúrgica.

- Existencia de uropatía obstructiva

- Existencia de vejiga neurogénica

- Paciente en período de estudio inicial hasta haber descartado eventuales anormalidades urinarias

- Lactante bajo un año de edad con pielonefritis aguda, durante el primer año de vida, por un mínimo de seis meses

que debiera ser estimulada ${ }^{2}$. La circuncisión como intervención para disminuir la tasa de ITU en varones es aún controversial, no habiendo hasta el momento estudios controlados y randomizados que certifiquen su utilidad ${ }^{3,13}$. El uso de sustancias acidificantes de la orina no han mostrado una gran utilidad para evitar la ITU, a excepción del jugo de arándano (cranberry), que pareciera tener una especial utilidad en este sentido ${ }^{13}$.

\section{Profilaxis antimicrobiana}

Si bien aún no existen ensayos clínicos bien realizados en este aspecto, la mayoría de los estudios demuestra una clara disminución en la tasa de recurrencias de ITU en pacientes en riesgo $\mathrm{o}^{3,5,9,13}$.

Se considera pertinente efectuar profilaxis antimicrobiana en las condiciones enumeradas en la Tabla 7.

La profilaxis se efectúa con nitrofurantoína en una dosis diaria de $2 \mathrm{mg} / \mathrm{kg} /$ día. En lactantes bajo tres meses de edad, en pacientes con intolerancia a la nitrofurantoína o en pacientes con clearance de creatinina menor de $35 \mathrm{ml} / \mathrm{min} / 1,73 \mathrm{~m}^{2}$ de superficie corporal, se puede utilizar cefadroxilo en dosis de $15 \mathrm{mg} / \mathrm{kg} / \mathrm{día}^{6}$.

\section{Estudio nefrourológico}

Todo niño que presente una infección urinaria bien documentada, sea alta o baja, independiente de su sexo y edad, debe ser sometido a un estudio imagenológico inicial con ultrasonografía renal y vesical y con uretrocistografía miccional (Figura 1). La única excepción a esta regla es la mujer sobre cinco años de edad, con un primer episodio de infección urinaria baja, a quien debe efectuársele sólo la ultrasonografía y, en casos que ésta resultara anormal, si la ITU fue febril o si presenta un segundo episodio de ITU, deberá completar su estudio con uretrocistografía $a^{2,3,5,6,14}$.
La uretrocistografía miccional puede efectuarse después de 72 horas de iniciado el tratamiento antimicrobiano, si un urocultivo de control intratratamiento es negativo.

Otros exámenes que pueden ser de utilidad y deben ser discutidos con el especialista, son el cintigrama renal estático (DMSA), método de elección para detectar compromiso parenquimatoso en la pielonefritis aguda o cicatrices renales, el cintigrama renal dinámico (DTPA o MAG3) para estudio de uropatías obstructivas y la urodinamia, indicada en ITU recurrente con estudio imagenológico normal, o en ITU asociada a sospecha de disfunción vesical, tanto clínica como radiológica $^{6,14}$.

\section{Seguimiento}

En pacientes afectados por una pielonefritis aguda debe efectuarse control de sedimento de orina y urocultivo al tercer día de iniciado el tratamiento antimicrobiano. Una vez terminado éste, tanto en caso de ITU baja como de pielonefritis aguda, se recomienda efectuar controles clínicos y exámenes de orina con cultivo al quinto día post tratamiento, luego en forma mensual por tres veces, luego bimestral por tres veces y luego semestral hasta completar dos años de seguimiento ${ }^{6}$.

\section{Criterios de derivación}

Debe ser derivado al especialista todo niño con ITU complicada, considerando como tal a:

- Recién nacidos independientemente de la evolución del episodio

- Lactantes y niños mayores con ecografía renal alterada o sospecha de alteración orgánica o funcional de vejiga

- Pacientes con reflujo vésico-ureteral u otra malformación del tracto urinario ${ }^{6}$. 


\section{Resumen}

La infección del tracto urinario (ITU) es una de las principales causas de infección bacteriana en niños. Un diagnóstico oportuno, un tratamiento adecuado y un seguimiento estrecho prevendrán el daño renal crónico. En este breve artículo se revisan sus características clínicas y las recomendaciones para el diagnóstico y tratamiento de acuerdo a la edad de cada paciente.

\section{Bibliografía}

1.- Ma J, Shortliffe L D. Urinary tract infection in children: etiology and epidemiology. Urol Clin North Am 2004; 31: 517-26.

2.- Riccabona M. Urinary tract infections in children. Curr Opin Urol 2003; 13: 59-62.

3.- Schlager T. Urinary tract infections in infants and children. Infect Dis Clin North Am 2003; 17: 353 65.

4.- Williams G, Lee A, Craig J. Antibiotics for the prevention of urinary tract infection in children: A systematic review of randomized controlled trials. J Pediatr 2001; 138: 868-74.

5.- American Academy of Pediatrics: Committee on Quality Improvement and Subcommittee on Urinary Tract Infection. Practice Parameter: The diagnosis, treatment, and evaluation of the initial urinary tract infection in febrile infants and young children. Pediatrics 1999; 103: 843-52

6.- Salas P, Álvarez E, Saieh C. Pautas de diagnóstico y tratamiento en infección urinaria en niños. Documento de la Rama de Nefrología de la Sociedad Chilena de Pediatría. Rev Chil Pediatr 2003; 74: 311-4.

7.- Comité de Microbiología Clínica, Sociedad Chilena de Infectología. Recomendaciones para el diagnóstico microbiológico de la infección urinaria. Rev Chil Infect 2001; 18: 57-63.

8.- Chon Ch, Lai F C, Shortliffe L M. Pediatrics urinary tract infection. Pediatr Clin North Am 2001; 48: 1441-59.
9.- Williams G J, Lee A, Craig J C. Long-term antibiotics for preventing recurrent urinary tract infection in children. Cochrane Database Syst Rev 2001 (4): CD001534.

10.- Lagomarsino E, Valenzuela A, Cavagnaro F. Insuficiencia renal crónica pediátrica en Chile. Encuesta nacional 2000. Evolución de 7 años. Arch Latin Nefr Ped 2002; 2: 200.

11.- Huicho L, Campos-Sánchez M, Alamo C. Metaanalysis of urine screening tests for determining the risk of urinary tract infection in children: CME Review Article. Pediatr Infect Dis J 2002; 21: 1-11.

12.- Graham J C, Galloway A. The laboratory diagnosis of urinary tract infection. J Clin Pathol 2001; 54: 9119.

13.- Craig J. Urinary tract infection: new perspectives on a common disease. Curr Opin Infect Dis 2001; 14: 309-13.

14.- Hoberman A, Charron M, Hickey R, Baskin M, Kearney D, Wald E. Imaging studies after a first febrile urinary tract infection in young children. N Engl J Med 2003; 348: 195-202.

15.- Pecile P, Miorin E, Romanello C, Falleti E, Valent F, Giacomuzzi F, et al. Procalcitonin: A marker of severity of acute pyelonephritis among children. Pediatrics 2004; 114: 249-54.

16.- Hoberman A, Wald E, Hickey R, Baskin M, Charron M, Majd M, et al. Oral versus initial intravenous therapy for urinary tract infections in young febrile children. Pediatrics 1999; 104: 79-86.

17.- Norton K. New imaging applications in the evaluation of pediatric renal disease. Curr Opin Pediatr 2003; 15: 186-90.

18.- Gauthier M, Chevalier I, Sterescu A, Bergeron S, Brunet S, Taddeo D. Treatment of urinary tract infections among young children with daily intravenous antibiotic therapy at a day treatment center. Pediatrics 2004; 114: 469-76.

19.- Malhotra S, Kennedy W. Urinary tract infections in children: treatment. Urol Clin North Am 2004; 31: 527-34.

20.- McBryde C, Redington J. Diagnosis and management of urinary tract infections: asymptomatic bacteriuria, cystitis, and pyelonephritis. Prim Care Case Rev 2001: 41; 3-14.

Correspondencia a:

Felipe Cavagnaro Santa María

fcavagna@med.puc.cl 